\section{International Scientific Journal Theoretical \& Applied Science}

Evgeniy Reutskiy

post graduate student

National aviation university, Ukraine evgeniyr@ukr.net

p-ISSN: 2308-4944 (print) e-ISSN: 2409-0085 (online)

Leonid Scherbak

doctor of technical science, professor National aviation university, Ukraine

Year: $2016 \quad$ Issue: 4 Volume: 36

Published: $30.04 .2016 \quad$ http://T-Science.org

SECTION 4. Computer science, computer engineering and automation.

\title{
THE METHOD OF FORECASTING CHARACTERISTICS OF MEASURING CHANNELS OF TECHNICAL SYSTEMS
}

Abstract: In this paper the method of forecasting characteristics of measuring channels of technical systems is offered and grounded. Using time series models autoregressive integrated moving average received forecast relative error. The results of forecasting are given.

Key words: forecasting, technical system, measuring channel, time series, ARIMA.

Language: English

Citation: Reutskiy E, Scherbak L (2016) THE METHOD OF FORECASTING CHARACTERISTICS OF MEASURING CHANNELS OF TECHNICAL SYSTEMS. ISJ Theoretical \& Applied Science, 04 (36): 21-25.

Soi: http://s-o-i.org/1.1/TAS-04-36-3 Doi: crossef http://dx.doi.org/10.15863/TAS.2016.04.36.3

\section{Introduction}

Modern technical systems are complex hardware-software complexes, consisting of a set of measuring channels, computer components, communication lines, means registration and display. The work of such systems in the technological process is necessary to study the characteristics of individual components to establish and maintain reliable operation.

During the transformation of information into components of technical systems and end user arrives to question its authenticity which affect measurement errors, errors in data transmission, imperfect lines and so on. In this regard the task for developing of forecasting method of the characteristics of measuring channels is urgent and important task.

\section{Formulation of the problem}

Problems of forecasting technical characteristics attracted the attention of researchers and scientists. In particular this applies to performance measurement channels that transmit important information about the system and its condition. The method of forecasting will use the estimation time series, which corresponds to the distribution characteristics. The correct classification and evaluation of characteristics of time series is the basis for further modeling, because the quality of the process that is modeled should accordingly be assessed and analyze statistical methods.

All series in its essence is a sequence of values of the series, received at certain times. Therefore, their characteristics are determined by way of measuring these values, characteristics measuring time intervals, stationary and memory [1]. Since we are dealing with values measurement specifications for the uneven amount of time (since the frequency measurement does not affect the result), it is now time series torque (torque matter, not interval indicator) and uneven over time. By the analysis we need to determine its stationary and memory (as a description of its autocorrelation). When choosing a method of forecasting should be based on the tasks that are before the forecast and the availability of resources for its implementation, especially in view of a significant number of these methods.

The best according to many researchers [2-6], and therefore the most popular for time series prediction for the short and medium term methods are neural networks (ANN) and autoregressive integrated moving average (ARIMA). Regressive and exponential smoothing methods are less effective short-term forecasts; the relative lack of neural networks is the unavailability of intermediate computation and complexity in the choice of learning algorithms, especially for a large number of random variables [7]. Since the ARIMA forecasting is an effective method of stationary and non-stationary linear processes, relatively easy to use and effective in the short and medium term, it will be used for forecasting characteristics of measuring channels. In this research must justify the method of forecasting performance precision measuring channels via 


\begin{tabular}{|c|c|c|c|c|c|c|}
\hline Impact Factor: & $\begin{array}{l}\text { ISRA (India) } \\
\text { ISI (Dubai, UAB } \\
\text { GIF (Australia) } \\
\text { JIF }\end{array}$ & $\begin{array}{r}=1.344 \\
=0.829 \\
=0.564 \\
=1.500\end{array}$ & $\begin{array}{l}\text { SIS (USA) } \\
\text { PИHЦ (Russia) } \\
\text { ESJI (KZ) } \\
\text { SJIF (Morocco) }\end{array}$ & $\begin{array}{l}=0.912 \\
=0.179 \\
=1.042 \\
=2.031\end{array}$ & $\begin{array}{l}\text { ICV (Poland) } \\
\text { PIF (India) } \\
\text { IBI (India) }\end{array}$ & $\begin{array}{l}=6.630 \\
=1.940 \\
=4.260\end{array}$ \\
\hline
\end{tabular}

technical systems and build time series forecasting model based testing.

\section{Results}

Time series using ARIMA models is as follows

$$
\begin{gathered}
y_{t}=\mu+a_{1} y_{t-1}+a_{2} y_{t-2}+\ldots \\
+a_{p} y_{t-p}+\varepsilon_{t}-\theta_{1} \varepsilon_{t-1}-\ldots-\theta_{q} \varepsilon_{t-q},
\end{gathered}
$$

where $y_{t}-$ level series; $\mu$ - constant; $p-$ order autoregression; $a_{1} \ldots a_{p}-$ autoregression coefficients; $\varepsilon_{t}-$ white noise; $\theta_{q}$ - weights.

When taking into account the trend of values instead of $y_{t}$ administered difference $\Delta^{1}\left(y_{t}\right)=y_{t}-y_{t-1} \mathrm{~d}$-order, for linear trend, for example, is $\Delta^{1}\left(y_{t}\right)=y_{t}-y_{t-1}$ and these differences must be stationary. Thus, the model ARIMA (p, d, q) as follows:

$$
\begin{aligned}
& \Delta^{d}\left(y_{t}\right)=\mu+a_{1} \Delta^{d}\left(y_{t-1}\right)+a_{2} \Delta^{d}\left(y_{t-2}\right)+ \\
& +a_{p} \Delta^{d}\left(y_{t-p}\right)+\varepsilon_{t}-\theta_{1} \varepsilon_{t-1}-\ldots-\theta_{q} \varepsilon_{t-q} .
\end{aligned}
$$

This model differ iterative approach to the formation predictive model. All of the parameters selected from the set of possible and thus selected a model that most accurately describes this time series with minimal dispersion. As a result of the research including a number of graphs and charts autocorrelation and partial correlation, sorting options is chosen ARIMA model base, on which is based the forecast. We will use for forecasting the relative error of measuring channel. The value of relative error has a Gaussian distribution, the absolute value of error ranged from $0.5 \%$ to $0.6 \%$, estimation of a random variable that will forecasting should be effective and appropriate.

As a random number generator will use the true random number generator (TRNG). The source of such numbers are physical phenomena, such as resource random.org generating source is atmospheric noise [3, 8].

We have formed 3 time series: Experiment 1, Experiment 2, Experiment 3.

1. Experiment $1-1000$ random numbers to within 0.00001 .

2. Experiment 2 - 1000 random numbers to within 0,001 . 0.0001 .

3. Experiment 3 - 100 random values to within

In the first two cases, we look at a fairly large number of random variables affect the accuracy of the forecast range (fig. 1, 2).
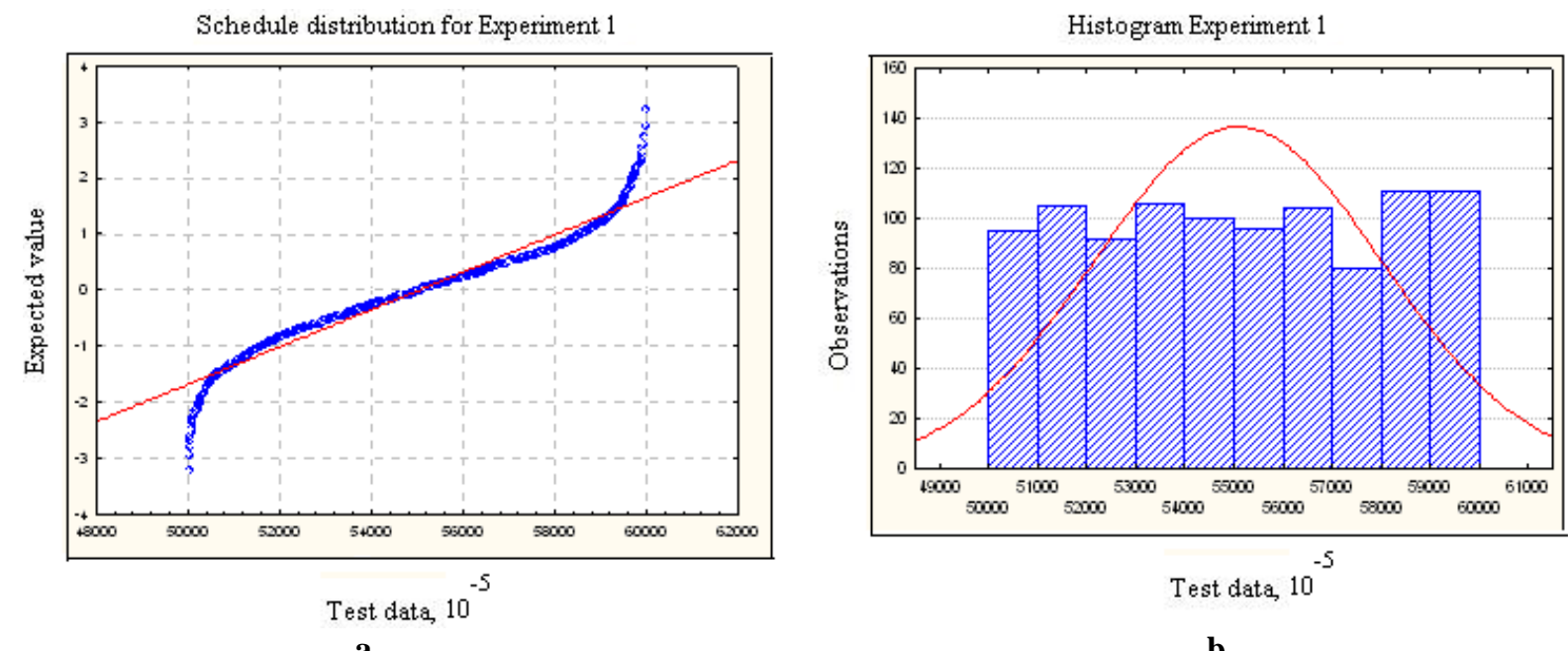

Figure 1 - Chart data distribution test Experiment 1: a - schedule distribution for Experiment 1, b - histogram Experiment 1. 


\begin{tabular}{l|lrl|l|ll} 
& ISRA (India) & $=\mathbf{1 . 3 4 4}$ & SIS (USA) & $=\mathbf{0 . 9 1 2}$ & ICV (Poland) & $=\mathbf{6 . 6 3 0}$ \\
Impact Factor: & ISI (Dubai, UAE) $=\mathbf{0 . 8 2 9}$ & PUHU (Russia) $=\mathbf{0 . 1 7 9}$ & PIF (India) & $=\mathbf{1 . 9 4 0}$ \\
& GIF (Australia) & $\mathbf{0 . 5 6 4}$ & ESJI (KZ) & $=\mathbf{1 . 0 4 2}$ & IBI (India) & $\mathbf{4 . 2 6 0}$
\end{tabular}

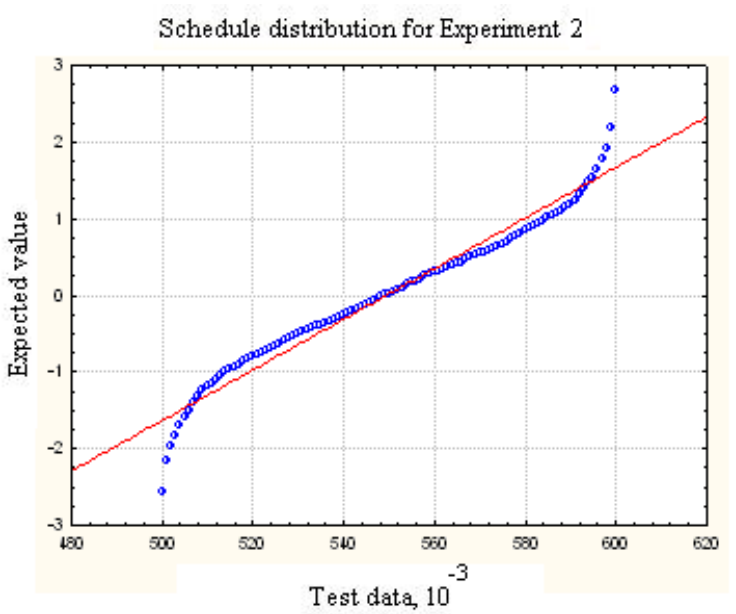

a

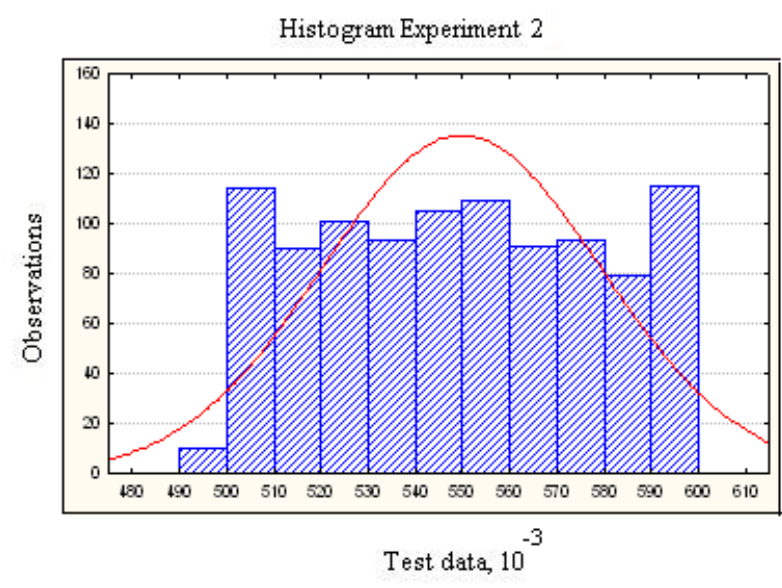

b

Figure 2 - Chart data distribution test Experiment 2: a - schedule distribution for Experiment 2, b - histogram Experiment 2.

The last case has taken us to compare, the relatively small number of observations with relatively high precision (fig. 3). For further research was chosen time series Experiment 1 and the model of ARIMA $(2,0,1)$. The next stage of research is to analyze the autocorrelation and partial autocorrelation functions which will highlight the trend.

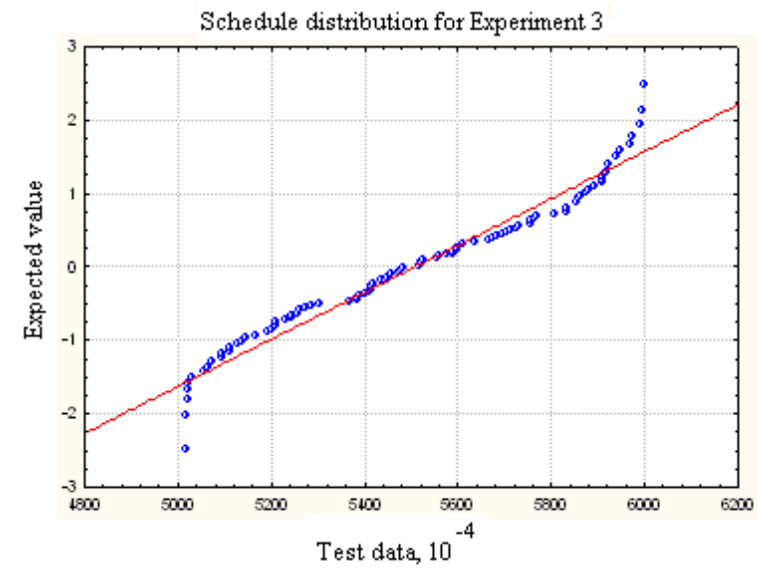

a

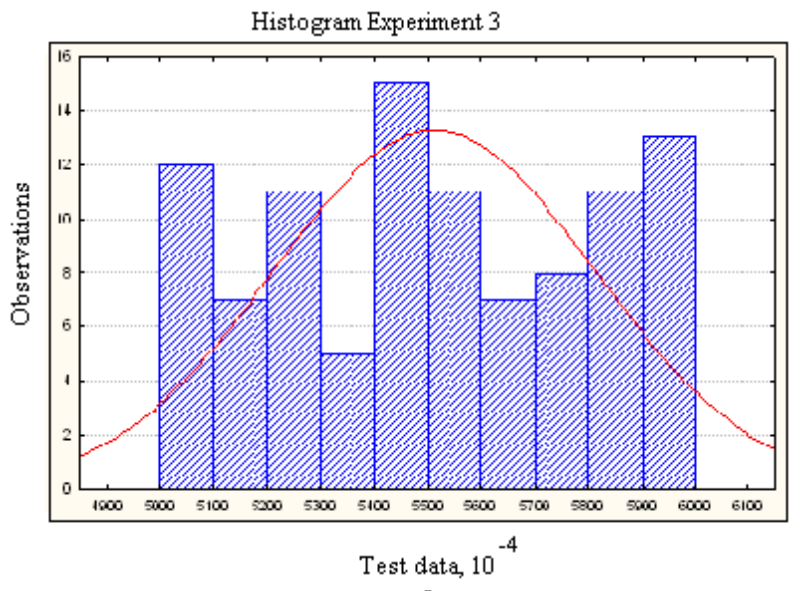

b

Figure 3 - Chart data distribution test Experiment 3: a - schedule distribution for Experiment 3, b - histogram Experiment 3.

Figure 4 shows an autocorrelation and partial autocorrelation functions. Figure 4 can be seen a single case going beyond the confidence interval. But since we are dealing with a very specific number, we can try to build a forecast model data parameters. 


\begin{tabular}{|c|c|c|c|c|c|c|}
\hline Impact Factor: & $\begin{array}{l}\text { ISRA (India) } \\
\text { ISI (Dubai, UAE } \\
\text { GIF (Australia) } \\
\text { JIF }\end{array}$ & $\begin{array}{l}=1.344 \\
=0.829 \\
=0.564 \\
=1.500\end{array}$ & $\begin{array}{l}\text { SIS (USA) } \\
\text { PИНЦ (Russia) } \\
\text { ESJI (KZ) } \\
\text { SJIF (Morocco) }\end{array}$ & $\begin{array}{l}=0.912 \\
=0.179 \\
=1.042 \\
=\mathbf{2 . 0 3 1}\end{array}$ & $\begin{array}{l}\text { ICV (Poland) } \\
\text { PIF (India) } \\
\text { IBI (India) }\end{array}$ & $\begin{array}{l}=6.630 \\
=1.940 \\
=4.260\end{array}$ \\
\hline
\end{tabular}
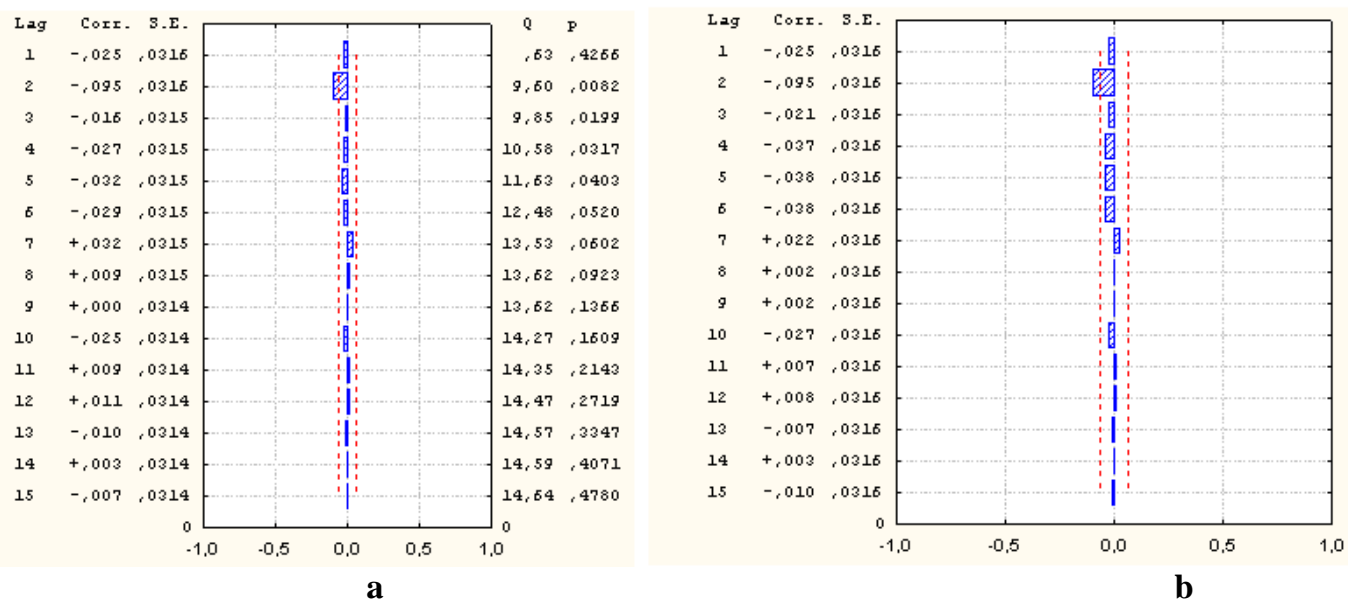

Figure 4 - Model ARIMA (2;0;1) Experiment 1: $a$ - autocorrelation function; $b$ - partial autocorrelation function

As we can see (Fig. 5) in our case we have a kind of average predictive value of real values of the schedule time series. This result is not entirely satisfactory, although the explanation for this prediction main reason is the complexity of the time series we have selected for prediction.

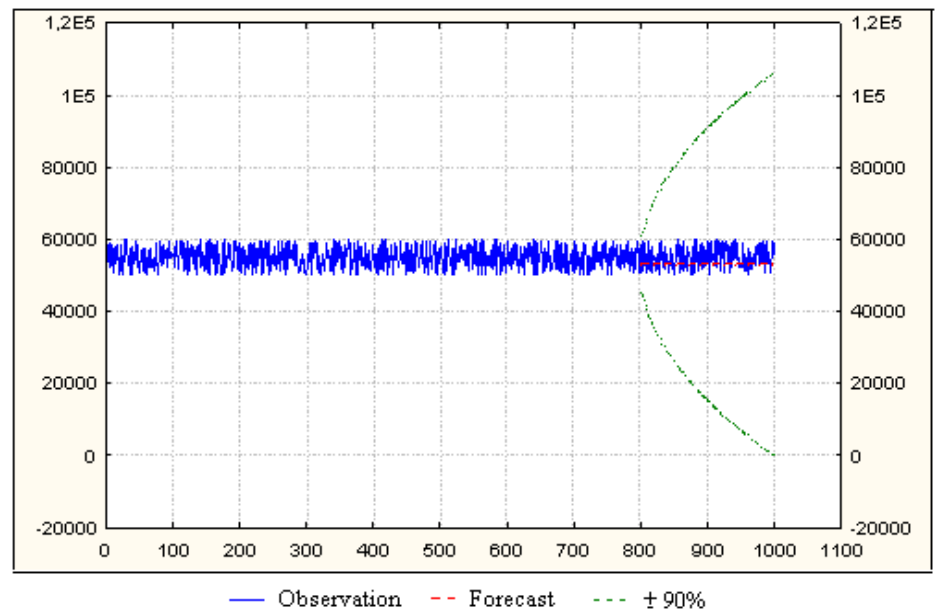

Figure 5 - Forecast ARIMA $(2,0,1)$ series Experiment 1 with a confidence interval 0.9

One way of improving the forecast is expanding forecasting tools. The consensus forecast is a combination of several projections performed by different organizations or specialists or by using different methods. The result is a prediction formed as a linear combination of independent forecasts.

\section{Conclusions}

In this article was based methods of forecasting the characteristics of measuring channels of technical systems using time series models ARIMA, used real random numbers generator. Based on the research the amount of data required parameters of the model and the accuracy of the forecast. We examined ways to improve the prognosis, as the possibility of using more than ARIMA method are alternative ways that may need to use in practice in case of low quality prediction, quantitative and qualitative characteristics of time series due to the nature of observations.

In further researches need to consider ways to improve the prognosis and the possibility of using other alternative methods to be used in practice, which can improve the accuracy in production processes. 


\begin{tabular}{l|lrl|l|ll} 
& ISRA (India) & $=\mathbf{1 . 3 4 4}$ & SIS (USA) & $=\mathbf{0 . 9 1 2}$ & ICV (Poland) & $=\mathbf{6 . 6 3 0}$ \\
Impact Factor: & ISI (Dubai, UAE) $=\mathbf{0 . 8 2 9}$ & PUHL (Russia) $=\mathbf{0 . 1 7 9}$ & PIF (India) & $=\mathbf{1 . 9 4 0}$ \\
& GIF (Australia) & $\mathbf{0 . 5 6 4}$ & ESJI (KZ) & $=\mathbf{1 . 0 4 2}$ & IBI (India) & $=\mathbf{4 . 2 6 0}$
\end{tabular}

\section{References:}

1. Boks D (2004) Analiz vremennyh ryadov. Prognoz i upravlenie / D. Boks, G. Dzhenkins. - Moscow: Mir, 2004. - 402 p.

2. Morariu N, Iancu E, Vlad S (2009) A neural network model for time series forecasting // Romanian Journal of Economic Forecasting. 2009, No. 4. pp. 213-223.

3. Parzen E (2004) Long memory of statistical time series modeling // NBER-NSF Time Series Conference, USA, Davis, 2004 [Elektronnyj resurs]. $\quad-\quad$ Available: http://www.stat.tamu.edu/ eparzen/Long\%20M emory\%20of\%20Statistical\%20Time\%20Series \%20Modeling.pdf (Accessed: 10.04.2016).

4. Norizan M, Maizah Hura A, Zuhaimy I (2010) Short Term Load Forecasting Using Double Seasonal ARIMA Model // Regional Conference on Statistical Sciences, Malaysia, Kelantan, 2010. pp. 57-73.

5. Reuc'kyj JA, Shherbak LM (2011) Metod prognozuvannja metrologichnyh harakterystyk dlja vyrishennja zavdan' nadijnosti zasobiv vymirjuvan' // Elektronika ta systemy upravlinnja. No 3(29). pp. 128 - 131.
6. Reutskiy EA (2014) The method of forecasting characteristics of metrological reliability informational-measuring systems / E.A. Reutskiy, L.M. Scherbak // ISJ Theoretical \& Applied Science. 2014. № 12(20). pp. 31 - 36. http://dx.doi.org/10.15863/TAS.2014.12.20.8

7. Collantes-Duarte J, Rivas-Echeverriat F (2002) Time Series Forecasting using ARIMA, Neural Networks and Neo Fuzzy Neurons // WSEAS International Conference on Neural Networks and Applications, Switzerland, 2002 [Elektronnyj resurs]. - Available: http://www.wseas.us/e-

library/conferences/switzerland2002/papers/464 .pdf (Accessed: 10.04.2016).

8. Von Neumann, John (1951) Various Techniques Used in Connection With Random Digits, 1951 [Elektronnyj resurs]. - Available: https://dornsifecms.usc.edu/assets/sites/520/doc s/VonNeumann-ams12p36-38.pdf (Accessed: 10.04.2016). 